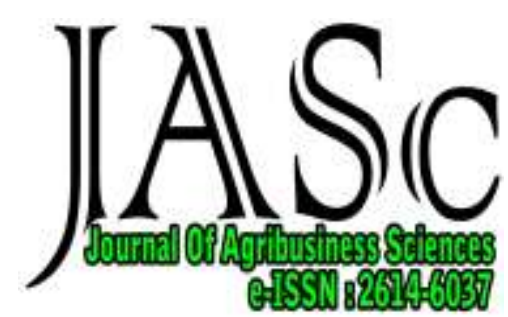

Oktober 2017 Volume 01 No. 01

\title{
THE STRATEGY of ECONOMIC DEVELOPMENT REGION BASE on THE LEADING SECTOR at KABUPATEN LANGKAT PROVINSI SUMATERA UTARA
}

\author{
STRATEGI PEMBANGUNAN EKONOMI WILAYAH BERBASIS SEKTOR \\ UNGGULAN DI KABUPATEN LANGKAT \\ PROVINSI SUMATERA UTARA
}

\author{
Desi Novita , Hartono Gultom \\ Program Studi Agribisnis \\ Fakultas pertanian Universitas Islam Sumatera Utara \\ Denovita_02@yahoo.co.id
}

\begin{abstract}
Economic development is an absolute process undertaken by a nation in improving the lives and welfare of the entire nation. Economic development that refers to the leading sectors will have an impact on the acceleration of economic growth. This research is done to determine the strategy and policy direction suitable to build the leading sector of langkat regency in order to increase economic growth of langkat regency.in the previous research it was found that the leading sector of langkat regency was agriculture forestry and fishery sector. The analysis method used in this research is descriptive SWOT analysis. Obtained some strategiest that are considered suitable for the development of agriculture forestry and fishery sector as the leading sector of langkat regency

Keyword : SWOT, leading sector, regional economic development
\end{abstract}

\section{ABSTRAK}

Pembangunan ekonomi merupakan suatu proses mutlak yang dilakukan oleh suatu bangsa dalam meningkatkan taraf hidup dan kesejahteraan seluruh bangsa tersebut. pembangunan ekonomi yang mengacu pada sektor unggulan akan berdampak pada percepatan pertumbuhan ekonomi. Penelitian ini dilakukan untuk menentukan strategi dan arah kebijakan yang cocok untuk membangun sektor unggulan wilayah kabupaten langkat agar dapat meningkatkan pertumbuhan ekonomi wilayah kabupaten langkat. Pada penelitian sebelumnya di peroleh bahwa sektor unggulan kabupaten langkat adalah sektor pertanian kehutanan dan perikanan. Metode analisis yang digunakan dalam penelitian ini adalah analisis SWOT. Dari hasil analisis diperoleh beberapa strategi yang dianggap cocok untuk membangun sektor pertanian kehutanan dan perikanan sebagai sektor unggulan kabupaten langkat.

Kata kunci : SWOT, sektor unggulan, strategi pembangunan ekonomi wilayah

\section{A. PENDAHULUAN}

Setiap daerah harus mampu mengoptimalkan potensi sumberdaya dengan sektor unggulan yang ada di daerahnya untuk mewujudkan pembangunan ekonomi di daerah tersebut. Pembangunan ekonomi daerah merupakan suatu kegiatan yang dilaksanakan oleh pemerintah daerah bersama-sama dengan masyarakat daerah, mengelola dan memanfaatkan sumberdaya yang ada secara optimal untuk merangsang perkembangan ekonomi daerah dan kesejahteraan masyarakat daerah. Salah satu tolak ukur keberhasilan pembangunan ekonomi dan pelayanan masyarakat di daerah dapat dilihat dari pertumbuhan ekonomi daerah tersebut.

Menurut Sjafrizal (2008) tolak ukur keberhasilan suatu pembangunan ekonomi daerah dapat dilihat dari beberapa indikator yaitu Produk Domestik Regional Bruto (PDRB) yang menjadi petunjuk kinerja perekonomian secara umum sebagai ukuran kemajuan suatu daerah, tingkat pertumbuhan, pendapatan perkapita dan pergeseran/perubahan struktur ekonomi. Pencapaian keberhasilan pembangunan daerah melalui pembangunan ekonomi harus disesuaikan dengan kondisi dan potensi masing-masing daerah serta diperlukan perencanaan pembangunan yang terkoordinasi antar sektor, perencanaan pembangunan disini bertujuan untuk menganalisis secara menyeluruh tentang potensi-potensi yang dimiliki oleh suatu daerah. Keterbatasan sumber daya di suatu daerah baik sumber daya alam, sumber daya manusia, sumber daya finansial maupun sumber daya lainnya merupakan masalah umum yang dihadapi oleh sebagian besar daerah untuk dapat menggerakkan seluruh perekonomian.

Untuk memacu laju pertumbuhan ekonomi regional serta meningkatkan kontribusinya terhadap pembentukan total Produk Domestik Regional Bruto (PDRB), maka pembangunan sektor unggulan dapat 


\section{Desi Novita , Hartono Gultom}

dijadikan sebagai penggerak pembangunan ekonomi. Secara umum tujuan pembangunan bidang ekonomi khususnya sektor unggulan adalah untuk mempercepat laju pertumbuhan ekonomi dengan demikian dapat tercipta stabilitas ekonomi yang sehat dan dinamis, dan tercipta kemakmuran dan kesejahteraan yang dinikmati oleh masyarakat daerah tersebut.

Kabupaten Langkat memiliki potensi yang cukup besar untuk dikembangkan. Selama ini banyak potensi di wilayah Kabupaten Langkat yang belum sepenuhnya dimanfaatkan. Sehingga menjadi sulitnya bagi Pemerintah daerah untuk menentukan prioritas sektor unggulan wilayah dalam mencanangkan pembangunan daerahnya. Apabila tidak dikembangkan dan dikelola maka pertumbuhan ekonomi Kabupaten Langkat akan menurun. Walaupun Kabupaten Langkat memiliki sumberdaya yang cukup besar, namun kondisi tersebut tidaklah mampu untuk memecahkan berbagai masalah pembangunan. Permasalahan yang dihadapi Pemerintah daerah, yaitu masih kesulitan untuk menetapkan kebijakan pembangunan terhadap sektor unggulan daerah. Seolah-olah Pemerintah daerah mengalami hambatan untuk memilih sektor yang mana yang harus dibangun terlebih dahulu.

Kabupaten langkat memiliki sektor unggulan yaitu pertanian kehutanan dan perikanan, namun semakin lama Struktur lapangan usaha sebagian masyarakat Kabupaten Langkat semakin bergeser dari lapangan usaha Pertanian, Kehutanan, dan Perikanan ke lapangan usaha ekonomi lainnya yang terlihat dari besarnya peranan masing-masing lapangan usaha ini terhadap pembentukan PDRB Kabupaten Langkat. Sumbangan terbesar pada tahun 2014 dihasilkan oleh lapangan usaha Pertanian, Kehutanan, dan Perikanan sebesar 41,96 persen; dan menyusul lapangan usaha Industri Pengolahan sebesar 15 persen, kemudian lapangan usaha Pertambangan dan Penggalian sebesar 9,87 persen

Sektor pertanian tidak lagi merupakan sektor yang sangat dominan bagi perekonomian maupun penyerapan tenaga kerja di Kabupaten Langkat maupun Provinsi Sumatera Utara. Perkembangan 2 tahun terakhir menunjukkan bahwa terjadi pergeseran dari sektor pertanian ke sektor service dalam penyerapan tenaga kerja. Pada tahun 2014 sebanyak 46,80 persen penduduk Kabupaten Langkat bekerja di sektor agriculture/pertanian, kemudian diikuti sektor service (angkutan, perdagangan, keuangan dan jasa) sebesar 39,36 persen dan sisanya 13,84 persen pada sektor manufacture (pertambangan/penggalian, industri, listrik gas dan air serta bangunan)
Pada tahun 2015 kondisinya relatif sama, yaitu pertanian tdak mendominasi lagi terjadi penurunan yaitu menjadi 39,75 persen, didominasi sektor service sebesar 45,25 persen serta sektor manufacture sebesar 15,00 persen. Besarnya peran sektor pertanian dalam perekonomian Kabupaten Langkat dan Provinsi Sumatera Utara karena memang memiliki potensi pertanian tanam pangan, peternakan, perkebunan, kehutanan dan perikanan yang didukung oleh lahan yang cukup luas dan subur. Oleh sebab itu ditentukan rumusan masalah dalam penelitian ini adalah bagaimana strategi dan kebijakan yang tepat untuk membangun sektor unggulan dalam meningkatkan perekonomian kabupaten langkat.

\section{B. METODE PENELITIAN}

Penelitian dilakukan di Kabupaten Langkat Provinsi Sumatera Utara. Pemilihan lokasi penelitian di Kabupaten Langkat dipilih secara purposive (sengaja), dengan pertimbangan bahwa Kabupaten Langkat merupakan kabupaten yang mempunyai potensi sumberdaya alam yang dapat dikelola untuk meningkatkan perekonomian dan pembangunan wilayah. Untuk memperoleh data primer dalam menganalisis permasalahan pada penelitian ini maka penarikan jumlah sampel di lakukan secara bebas, dan penentuan sampel dengan menentukan stakeholder - stakeholder yang berkaitan dengan sektor unggulan kabupaten langkat dan dinas - dinas pemerintah yang bersangkutan dengan pengembangan sektor unggulan di kabupaten langkat. Data yang di peroleh berupa hasil wawancara.

\section{Analisis SWOT}

Analisis SWOT digunakan untuk menjawab permasalahan yaitu strategi dan kebijakan apa yang dapat di gunakan membangun wilayah kabupaten langkat pada sektor unggulan. Analisis SWOT merupakan identifikasi yang bersifat sistematis dan dapat menyelaraskan faktor-faktor dari lingkungan internal dan eksternal serta dapat mengarahkan dan berperan sebagai kaatalisator dalam proses perencanaan startegis. Analisis SWOT dilaksanakan dengan memfokuskan pada dua hal, yaitu peluang dan ancaman serta identifikasi kekuatan dan kelemahan intern. Analisis ini didasarkan pada asumsi bhwa suatu strategi yang efektif akan memaksimalkan kekuatan dan peluang serta meminimalkan kelemahan dan ancaman (Perce dan Robinson dalam M. gufrhon, 2008).

Unsur-unsur SWOT meliputi S (strenght) yang berrti mengacu kepada keunggulan kompetitif dan kompetensi lainnya, $\mathrm{W}$ (weakness) yaitu hambatan yang membatasi pilihan-pilihan pada pengembangan strategi, $\mathrm{O}$ 


\section{STRATEGI PEMBANGUNAN EKONOMI WILAYAH BERBASIS SEKTOR UNGGULAN}

(opportunity) yakni menyediakan kondisi yang menguntungkan atau peluang yang membatasi penghalang dan $\mathrm{T}$ (threat) yang berhubungan dengan kondisi yang dapat menghalangi atau ancaman dalam mencapai tujuan. Matriks ini dapat menghasilkan empat sel kemungkinan alternatif strategi, yaitu strategi S-O, strategi WO, strategi W-T dan strategi S-T. Terdapat delapan tahap dalam membentuk matriks SWOT, yaitu:

1. Membuat daftar kekuatan kunci internal wilayah.

2. Membuat daftar kelemahan kunci internal wilayah.
3. Membuat daftar peluang ekternal wilayah.

4. Membuat daftar ancaman ekternal wilayah.

5. Menyesuaikan kekuatan-kekuatan internal dengan peluang-peluang ekternal dan mencatat hasilnya dalam sel strategi S-O.

6. Menyesuaikan kelemahan-kelemahan internal dengan peluang-peluang eksternal dan mencatat hasilnya dalam sel strategi W-O.

7. Menyesuaikan kekuatan-kekuatan internal dengan ancaman-ancaman eksternal dan mencatat hasilnya dalam sel strategi S-T.

8. Menyesuaikan kelemahan-kelemahan internal dengan ancaman-ancaman eksternal dan mencatat hasilnya dalam sel strategi W-T.

Tabel Matriks SWOT

\begin{tabular}{|c|c|c|}
\hline Eksternal & $\begin{array}{l}\text { STRENGTH (S) } \\
\text { Daftar Kekuatan } \\
\text { Internal }\end{array}$ & $\begin{array}{l}\text { WEAKNESS (W) } \\
\text { Daftar Kelemahan } \\
\text { Internal }\end{array}$ \\
\hline $\begin{array}{c}\text { OPPORTUNITIES(O) } \\
\text { Daftar Peluang } \\
\text { Eksternal }\end{array}$ & $\begin{array}{c}\text { STRATEGI S-O } \\
\text { Gunakan kekuatan untuk } \\
\text { memanfaatkan peluang }\end{array}$ & $\begin{array}{c}\text { STRATEGI W-O } \\
\text { Mengatasi kelemahan } \\
\text { dengan memanfaatkan } \\
\text { peluang }\end{array}$ \\
\hline $\begin{array}{l}\text { THREATS (T) } \\
\text { Daftar Ancaman } \\
\text { Eksternal }\end{array}$ & $\begin{array}{c}\text { STRATEGI S-T } \\
\text { Gunakan kekuatan untuk } \\
\text { menghindari ancaman }\end{array}$ & $\begin{array}{c}\text { STRATEGI W-T } \\
\text { Meminimalkan } \\
\text { kelemahan dan } \\
\text { menghindari ancaman }\end{array}$ \\
\hline
\end{tabular}

(M. Gufrhon, 2008)

\section{HASIL PENELITIAN}

Sebagai sektor basis di daerah kabupaten langkat pertanian perikanan dan kehutanan sudah serta sektor pengadaan listrik dan gas seharusnya dikembangkan sebagai salah satu pengembangan ekonomi di daerah kabupatan langkat, hal ini sesuai dengan strategi pembanguna ekonomi dimana Pembangunan terhadap sektor unggulan dapat meningkatkan pertumbumah ekonomi wilayah kabupaten langkat. Dengan melukuan pembangunan terhadap sektor unggulan bukan berarti pemerintah pusat maupun setempat mengabaikan sektor lain yang yang masih bisa dikembangkan untuk mendukung sektro unggulan yang sudah ada.

Untuk melakukan pembangunan sendiri perlu dilakukan strategi dan kebijakan pembangunan yang efektif dan efesien agar pembangunan dapat dilakukan meksimal dan memiliki manfaat terhadap pembagunan wilayah. Sesuai dengan rumusan masalah yaitu Bagaimana strategi dan kebijakan yang tepat untuk membangun Kabupaten Langkat yang berbasis pada sektor unggulan daerah, untuk mejawab permasalahan tersebut sesuai dengan data yang di peroleh melalui wawancara kuisioner dan memperoleh data rencana pembangunan jangka menengah daerah (RPJMD) yang di peroleh dari BAPPEDA, setelah mengamati kondisi internal dan eksternal baik peluang maupun ancaman maka di peroleh beberapa strategi dan kebijakan pembangunan terhadap sektor unggulan kabupaten langkat melalui analisis SWOT sebagai berikut 
Tabel Analisis SWOT

\begin{tabular}{|c|c|c|}
\hline Eksternal & $\begin{array}{l}\text { STRENGTH/KEKUATAN (S): } \\
\text { 1. Potensi sumber daya alam yang } \\
\text { besar } \\
\text { 2. Ketersediaan produk pertanian } \\
\text { 3. Letak geografis wilayah yang } \\
\text { mendukung } \\
\text { SDM yang potensial untuk di } \\
\text { kembangkan } \\
\text { 5. Luasnya sentra produksi pertanian } \\
\text { dan perkebunan } \\
\text { 6. Koordinasi antar lembaga dan } \\
\text { dinas pertanian }\end{array}$ & 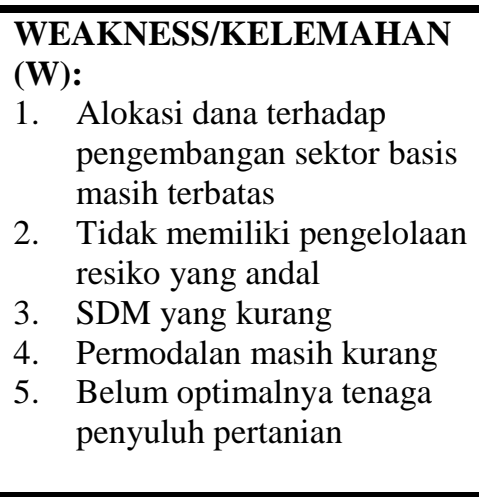 \\
\hline $\begin{array}{l}\text { OPPORTUNITIES/PELUAN } \\
\text { G (O) : } \\
\text { 1. } \begin{array}{l}\text { Dukungan dari pemerintah } \\
\text { pusat dalam memajukan }\end{array} \\
\text { sektor basis } \\
\text { 2. } \begin{array}{l}\text { Minat investor yang besar } \\
\text { di sektor basis }\end{array} \\
\text { 3. } \begin{array}{l}\text { Tingkat perkembangan } \\
\text { teknologi di bidang }\end{array} \\
\text { pertanian } \\
\text { 4. } \begin{array}{l}\text { Adanya kebijakan dari } \\
\text { pemerintah untuk }\end{array} \\
\text { pembangunan dan } \\
\text { pengembangan } \\
\text { Semakin meningkatnya } \\
\text { permintaan terhadap } \\
\text { produk pertanian }\end{array}$ & 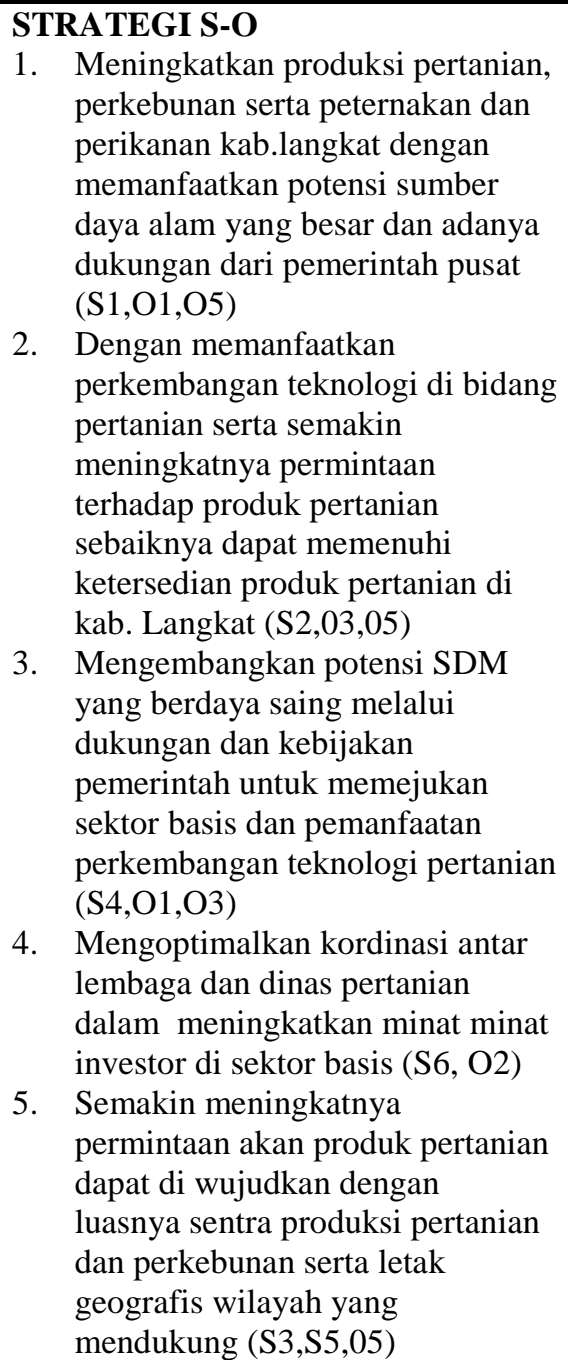 & 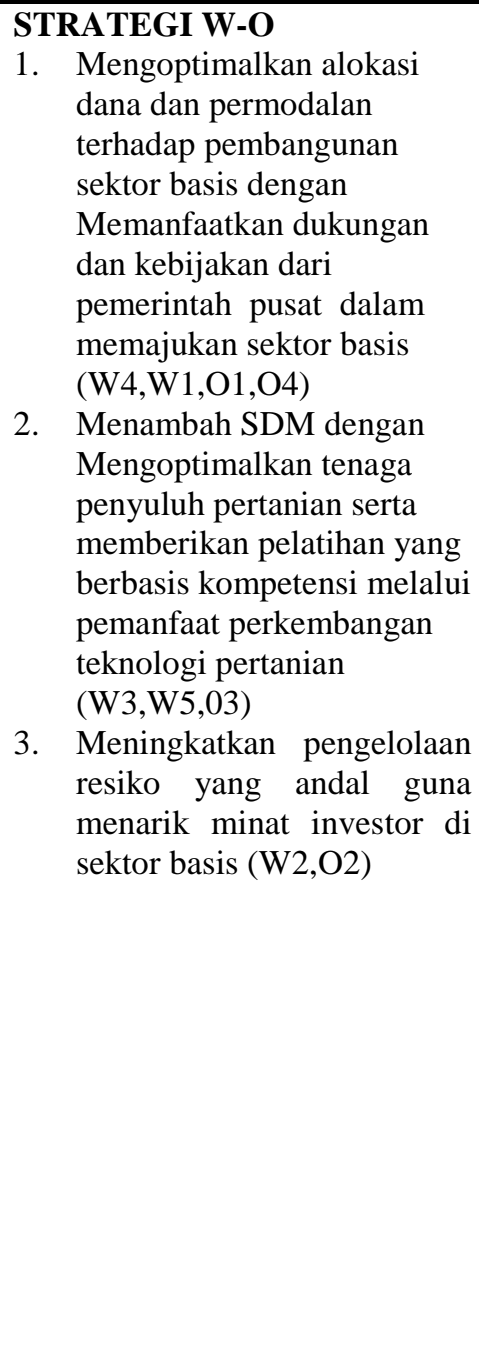 \\
\hline $\begin{array}{l}\text { THREATS / ANCAMAN (T) } \\
\text { 1. Bencana alam dan gagal } \\
\text { panen } \\
\text { 2. Era globalisasi yang } \\
\text { menuntut daya saing } \\
\text { 3. Ketidakpastian perolehan } \\
\text { hasil produksi } \\
\text { 4. Adanya gangguan } \\
\text { terhadap hasil produksi } \\
\text { (panen) } \\
\text { 5. Masih tingginya alih }\end{array}$ & 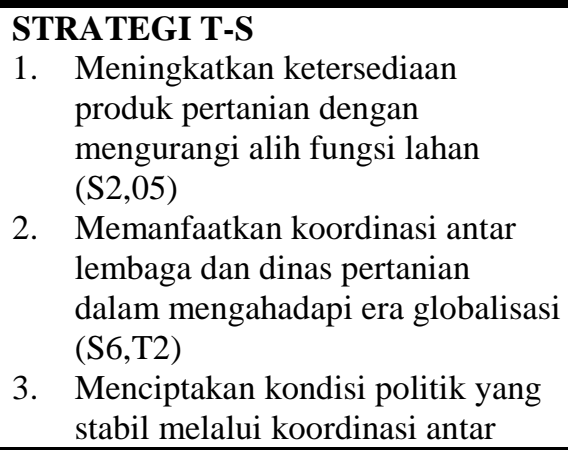 & 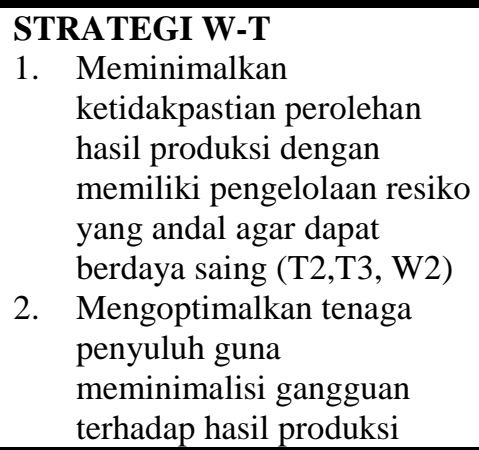 \\
\hline
\end{tabular}




\section{STRATEGI PEMBANGUNAN EKONOMI WILAYAH BERBASIS SEKTOR UNGGULAN}

\begin{tabular}{|c|c|c|}
\hline fungsi lahan. & $\begin{array}{l}\text { lembaga dan dinas pertanian yang } \\
\text { baik (T4,S6) } \\
\text { 4. Meminimalisir bencana alam dan } \\
\text { gagal panen serta gangguan } \\
\text { terhadap hasil produksi dengan } \\
\text { memanfaatkan letak geografis } \\
\text { wilayah yang mendukung } \\
(\mathrm{T} 1, \mathrm{~T} 5, \mathrm{~S} 3)\end{array}$ & $\begin{array}{ll}\text { 3. } & \text { Meminimalisir tingginya } \\
\text { laih fungsi lahan pertanian } \\
\text { serta meningkatkan tenaga } \\
\text { - tenaga penyuluh pertanian } \\
\text { (T5,W5) } \\
\text { 4. } \\
\text { Meminimalisir bencana } \\
\text { gagal panen dengan } \\
\text { meningkatkan pengelolaan } \\
\text { resiko yang andal (W2,T1) } \\
\text { Meningkatkan penggunaan } \\
\text { alokasi dana dan } \\
\text { permodalan guna mengatasi } \\
\text { ketidakpastian perolehan } \\
\text { hasil produksi serta } \\
\text { ganguan terhadap hasil } \\
\text { prodiksi (W1,W3,T3,T4) }\end{array}$ \\
\hline
\end{tabular}

Sasaran, strategi dan arah kebijakan pembangunan ekonomi masyarakat kabupaten langkat melalui sektor unggulan yang berdaya saing dapat di wujudkan dengan beberapa strategi utama serta arah kebijakan yang dapat di lakukan berdasarkan analisis SWOT dan penyesuaian dengan strategi yang ada di RPJMD kabupaten Langkat, maka Adapun Grand Strategi dan Kebijakan Pembangunan Kabupaten Langkat antara lain :

Tabel Penentuan Grand Strategi dan kebijakan pembangunan kab. langkat

\begin{tabular}{|c|c|c|c|}
\hline TUJUAN & SASARAN & STRATEGI & ARAH KEBIJAKAN \\
\hline \multirow[t]{5}{*}{$\begin{array}{l}\text { Meningkatkan } \\
\text { daya saing } \\
\text { ekonomi } \\
\text { kerakyatan } \\
\text { berbasis sektor } \\
\text { unggulan }\end{array}$} & \multirow[t]{4}{*}{$\begin{array}{l}\text { Meningkatkan } \\
\text { produksi } \\
\text { pertanian, } \\
\text { perkebnan, } \\
\text { perikanan dan } \\
\text { peternakan }\end{array}$} & $\begin{array}{l}\text { Meningkatkan } \\
\text { pertumbuhan sektor } \\
\text { pertanian tanaman } \\
\text { pangan }\end{array}$ & $\begin{array}{ll}- & \text { Mempertahankan tingkat produksi } \\
\text { pangan di kabupaten langkat } \\
\text { - } & \text { Peningkatan kualitas SDM pertanian } \\
\text { - } & \text { Menghidupkan dan memperkuat } \\
\text { lembaga pertanian } \\
\text { - } & \text { Mengurangi alih fungsi lahan dengan } \\
\text { menetapkan peraturan tentang alih } \\
\text { fungsi lahan }\end{array}$ \\
\hline & & $\begin{array}{l}\text { Menigkatkan } \\
\text { produksi tanaman } \\
\text { perkebunan }\end{array}$ & $\begin{array}{ll}\text { - } & \text { Peningkatan produksi tanaman } \\
\text { perkebunan utama } \\
\text { - } & \text { Fasilitasi pembiayaan dan pembinaan } \\
\text { bagi usaha perkebunan, khususnya } \\
\text { perkebunan rakyat } \\
\text { - Menghidupkan dan memperkuat } \\
\text { lembaga petani kebun }\end{array}$ \\
\hline & & $\begin{array}{l}\text { Meningkatkan } \\
\text { produksi dan } \\
\text { produktivitas } \\
\text { peternakan }\end{array}$ & 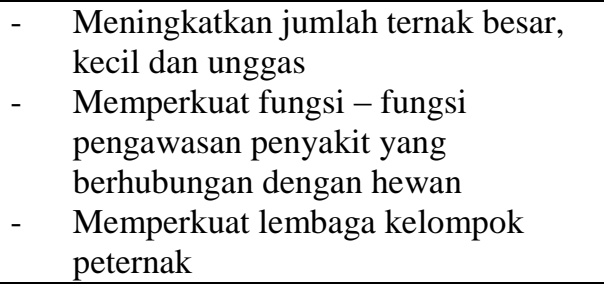 \\
\hline & & $\begin{array}{l}\text { Meningkatkan } \\
\text { pertumbuhan sub- } \\
\text { sektor perikanan }\end{array}$ & $\begin{array}{ll}\text { - } & \text { Peningkatan produksi perikanan } \\
\text { tangkap dan budidaya ikan } \\
\text { - } \quad \text { Peningkatan system kelembagaan } \\
\text { nelayan, pembudidaya dan pengelola } \\
\text { ikan }\end{array}$ \\
\hline & $\begin{array}{l}\text { meningkatkan } \\
\text { pemenuhan } \\
\text { infrastruktur } \\
\text { dasar wilaya }\end{array}$ & $\begin{array}{l}\text { Meminimalisir } \\
\text { bencana alam dan } \\
\text { gagal panen serta } \\
\text { gangguan terhadap } \\
\text { hasil produksi }\end{array}$ & $\begin{array}{l}\text { - } \\
\text { dalam kesiapsiagaan penanggulangan } \\
\text { bencana dan pengendalian bencana } \\
\text { alam, persiapan kedaruratan dan } \\
\text { logistic penanggulangan bencana }\end{array}$ \\
\hline
\end{tabular}




\section{Desi Novita , Hartono Gultom}

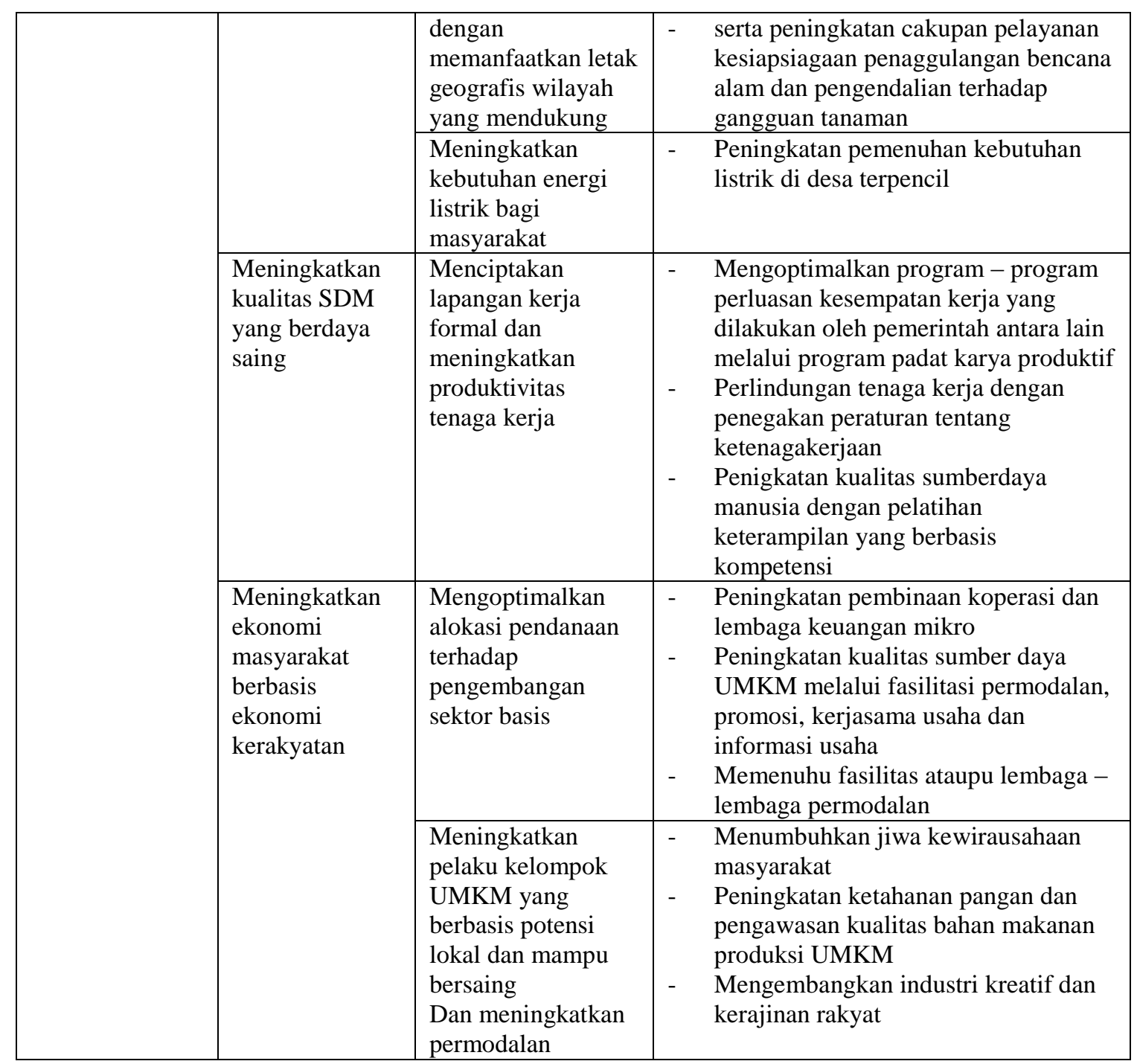

\section{KESIMPULAN}

Strategi dan arah kebijakan pembangunan ekonomi masyarakat kabupaten langkat melalui sektor unggulan yang berdaya saing dapat di wujudkan dengan beberapa strategi utama berdasarkan hasil dari analisis swot dan kebijakan yang diperoleh dari RPJMD kabupaten langkat yang dapat di lakukan antara lain : 1. Meningkatkan pertumbuhan sektor pertanian tanaman pangan, 2. Menigkatkan produksi tanaman perkebunan, 3. Meningkatkan Meningkatkan produksi dan produktivitas peternakan, 4. Meningkatkan pertumbuhan subsektor perikanan, 5. Meminimalisir bencana alam dan gagal panen serta gangguan terhadap hasil produksi dengan memanfaatkan letak geografis wilayah yang mendukung, 6 . Menciptakan lapangan kerja formal dan meningkatkan produktivitas tenaga kerja, 7 . Mengoptimalkan alokasi pendanaan terhadap pengembangan sektor basis, 8. Meningkatkan pelaku kelompok UMKM yang berbasis potensi lokal dan mampu bersaing Dan meningkatkan permodalan

\section{DAFTAR PUSTAKA}

Sjafrizal, 2008, "Ekonomi Regional: Teori dan Aplikasi”, Baduose Media Padang,

Arsyad, L, 1999 (dalam Dillah Novrilasari), Pengantar Perencanaan dan Pebangunan Ekonomi Daerah, UGM, Yogyakarta,

Badan Pusat Statistik Kabupaten Langkat, 2015, Kabupaten Langkat dalam Angka 2015 ,

BAPPEDA, 2017, rencana pembangunan jangka menengah daerah kabupaten langkat tahun 20142019, kabupaten langkat

M, ghufron, 2008 analisis pembangunan wilayah berbasis sektor unggulan kabupaten lamongan provinsi jawa timur, skripsi ekonomi pertanian dan sumber daya, IPB, Bogor 


\section{STRATEGI PEMBANGUNAN EKONOMI WILAYAH BERBASIS SEKTOR}

UNGGULAN

Rachbini, Didik J, 2001, Pembangunan Ekonomi \& Sumber Daya Manusia, Gramedia Widiasarana Indonesia, Jakarta,

Raharjo Adisasmita 2014, Pertumbuhan wilayah dan wilayah pertumbuhan, Graha Ilmu Indonesia, Yogyakarta
Usya, N, 2006, Analisis Struktur Ekonomi dan Identifikasi Sektor Unggulan di Kabupaten Subang, Fakultas Ekonomi dan Manajemen, IPB, Bogor

Tambunan, T,T,H, 2001, Perekonomian Indonesia, Ghalia Indonesia, Jakarta 